\title{
sciendo AVERAGE FUEL CONSUMPTION BY A SHIP ON A SALES LINE IN STATISTICAL WEATHER CONDITIONS
}

DOI 10.2478/ntpe-2018-0072

\author{
prof. dr hab. inż. Tadeusz Szelangiewicz \\ dr hab. inż. Katarzyna Żelazny, prof. AM \\ Maritime University of Szczecin, Poland
}

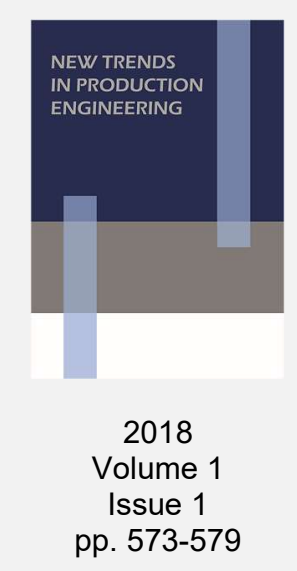

\begin{abstract}
During operation of the ship, fuel consumption and associated emissions are very important for economic and ecological reasons. The fuel consumption is greatly influenced by the choice of shipping route, weather conditions on these routes and engine control criteria. The article presents its own algorithm for forecasting ship operation parameters, including fuel consumption on selected shipping routes for average, statistical (seasonal) weather parameters occurring on these routes. It shows what factors have the main impact on fuel consumption and how you can affect fuel consumption during the cruise in changing weather conditions.
\end{abstract}

Keywords: fuel consumption, ship speed, propulsion power, shipping lines, average statistical weather parameters

\section{INTRODUCTION}

During ship operation, oceanic route forecasting is conducted according to various criteria (Wiśniewski, 1991). One of them is to minimize fuel consumption.

Nowadays, fuel consumption and associated emissions are very important due to operating costs and environmental protection. In the literature on this issue various algorithms for calculating fuel consumption are presented (Geertsma et al., 2017, Białostocki and Konovessis, 2016, Myung-II R, 2013). Also specialized computer systems such as: SPOS (SPOS Program, 2009) (Ship Performance Optimization System) or BON VOYAGE (Bon Voyage System, 2016, Szymański and Wiśniewski, 2016) calculate the fuel consumption for the forecasted route. However, the algorithms for calculating fuel consumption presented in the literature and used in the computed systems are very simplified and do not contain various methods (criteria) for controlling the propulsion engine. Correct determination of fuel consumption is of particular importance when sailing in variable weather conditions, when there is a large additional resistance and a decrease in the speed of the ship.

The article presents the results of calculations of average fuel consumption during a voyage of a vessel having a shipping line on which statistical weather parameters occur. The calculations were made according to our own algorithm containing calculations of additional resistance and decrease of speed as well as power and fuel consumption while sailing the ship in variable weather conditions.

\section{THE CONTROL CRITERIA OF THE ENGINE}

Fuel consumption: hourly $B_{h}$ (1) or daily $B_{D}$ (2) depends on the specific fuel consumption $g$ and on the power $N$ and engine speed $n$, resulting from the position of the working point in the engine field, Fig. 1. 


\section{CMCR}

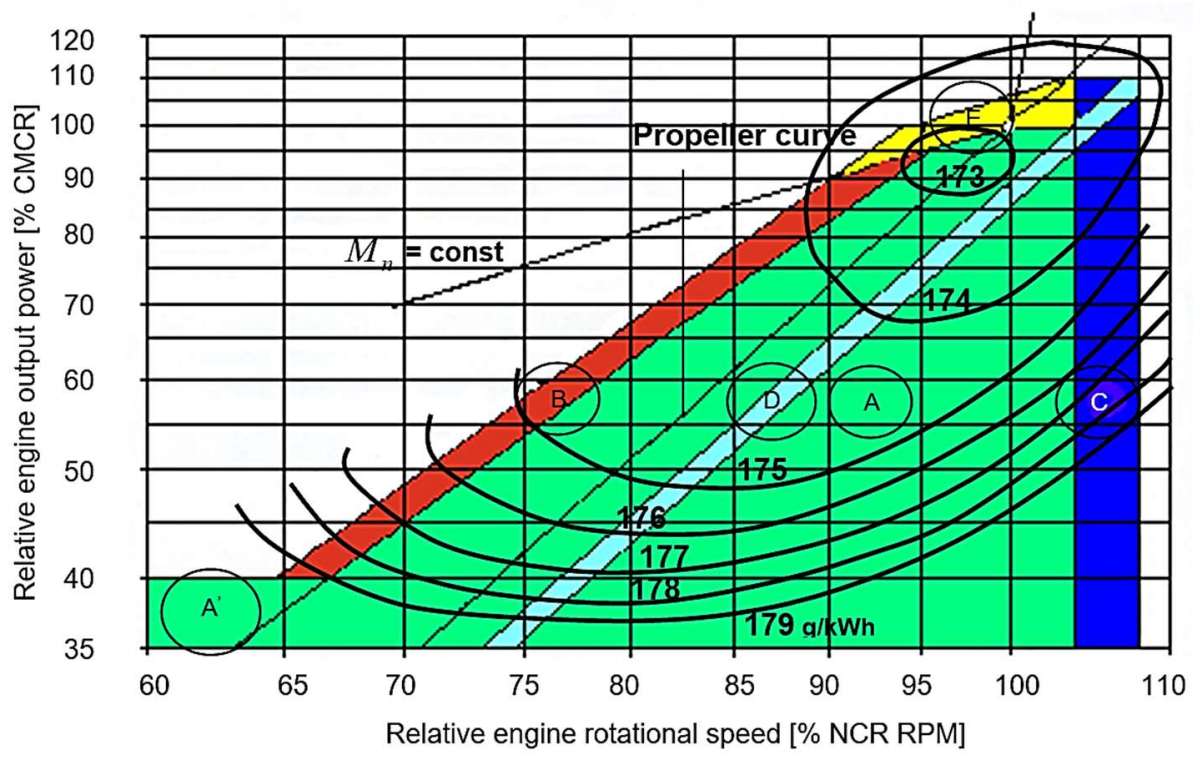

Fig. 1. The load area of an example low-speed propulsion engine:

$M_{n}$ - nominal torque, A - continuous rating area (marked green),

B - engine overloading area (red), C - engine sea trial operation area (deep blue),

D - engine optimum still-water operation area (blue),

E - engine instantaneous operation area (yellow)

Hourly fuel consumption is as follows:

$$
B_{h}=g(N, n) \cdot N \text {, }
$$

and daily:

$$
B_{D}=\sum_{1}^{24} B_{h},
$$

where:

- $g(N, n)$ - the specific fuel consumption depends on the instantaneous power $N$ and the rotational speed $n$ of the drive motor,

- $\quad N$ - instantaneous power of the engine.

Therefore, in order to calculate hourly or daily fuel consumption, it is necessary to know for a given engine the position of the operating point and the characteristics $g(N, n)$ of specific fuel consumption (Yuankang and Shipyard, 1993). The working point depends on the adopted criterion of engine control and on the momentary weather parameters on which the temporary, total resistance of the ship depends.

Possibilities of changing the operating point of the propulsion system (fixed pitch propeller) caused by the increase of additional resistance, eg when the ship is going upwind, is presented in (Szelangiewicz and Żelazny, 2008). In the described example, the ship is sailing on calm water at a given speed. Then an additional resistance arises from the wind blowing from the bow. In this situation, depending on the criterion adopted, the following transitions from the current work point to the new operating point of the drive system are possible:

criterion 1 - constant speed behavior - to compensate for the increase in ship's resistance, the fuel dose increases, at which the engine power increases accordingly, eventually the speed of the ship decreases;

criterion 2 - maintaining the ship's constant speed - to compensate for the increase in ship's resistance, the fuel dose increases, at which the engine power increases and the speed increases;

criterion 3 - maintaining the constant engine power - to compensate for the increase in ship's resistance, the engine speed decreases, eventually the speed of the ship decreases;

criterion 4 - maintaining a constant unit fuel consumption - to compensate for the increase in ship's resistance, the engine speed decreases with the simultaneous increase of engine power, eventually the speed of the ship decreases. 
For each of the listed criteria, it is possible to maintain constant values up to the limit curve defining the continuous field for a given engine (Fig. 1).

The achievement of a new working point of the propulsion system of the ship with increasing resistance, in this case wind speed, may be used with any other criterion for forecasting the route of sailing of the ship, e.g.: constant speed of the ship, maximum possible speed of the ship, minimum fuel consumption or constant or maximum efficiency of the propeller.

\section{LOCATION OF A DRIVE MOTOR WORK POINT IN VARIABLE WEATHER CONDITIONS}

Calculations of the position of the working engine's operating point, its power, instantaneous fuel consumption and speed of the ship in variable weather conditions were made according to the own algorithm for:

- a container ship,

- using the characteristics of the specific fuel consumption of the propulsion engine installed on the ship (Fig. 1),

- various criteria (variants) of engine control by changing the fuel dose in variable weather conditions (markings of directions of the marine environment and ship's course - Fig. 2).

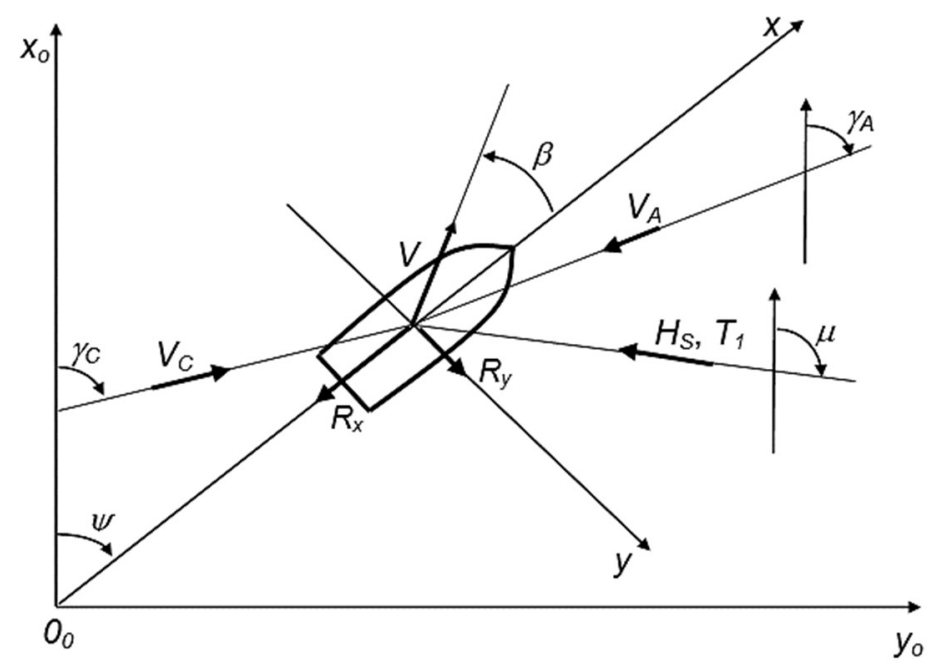

Fig. 2. Directions of the current, wind, wave and speed of the ship with the drift angle.

The results of ship speed, engine power and hourly fuel consumption (1) calculations for a specific engine work point, for variable weather parameters determined by the Beaufort number (BN) and for four engine control criteria, are shown in Figures 3-5.

Criterion 1 - constant rotation speed of the propeller

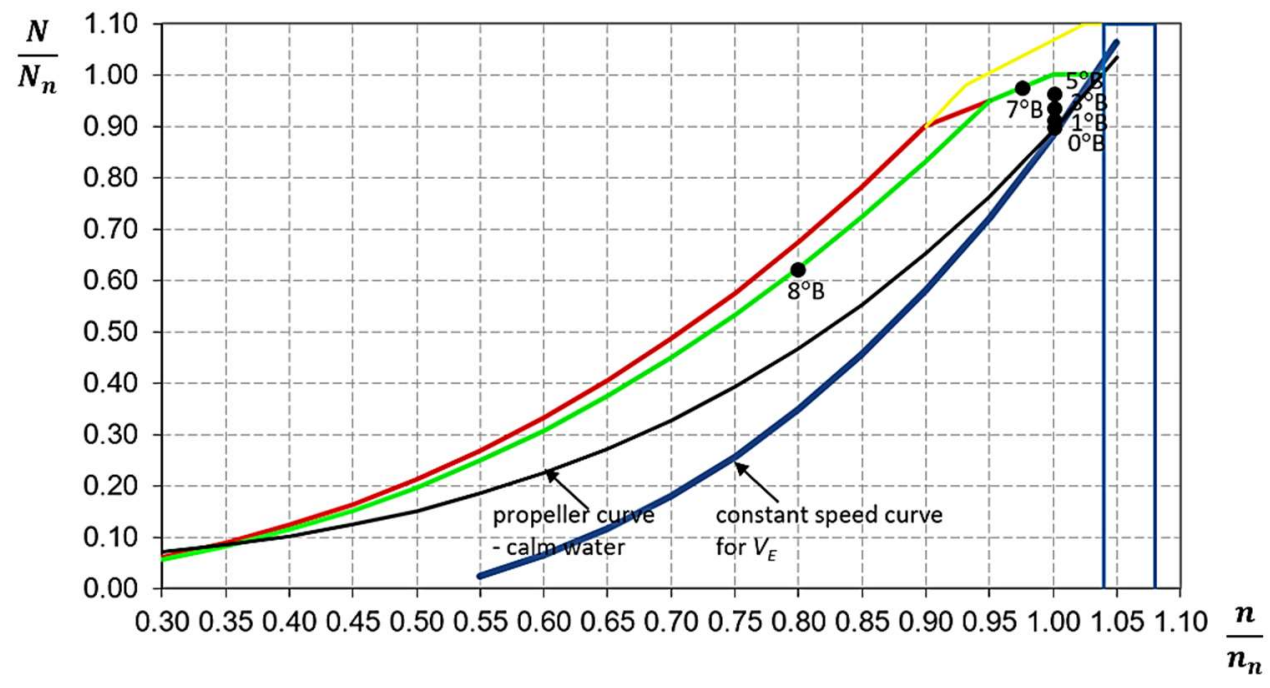


Criterion 2 - constant speed of the ship

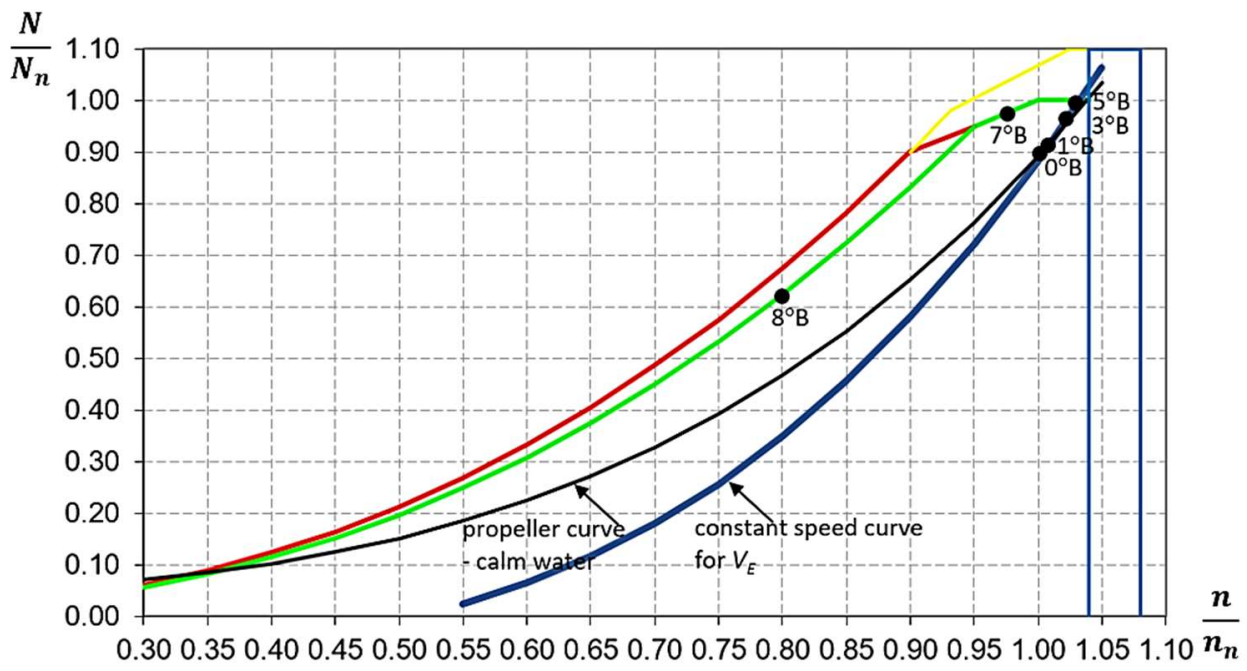

Criterion 3 - constant of the engine power

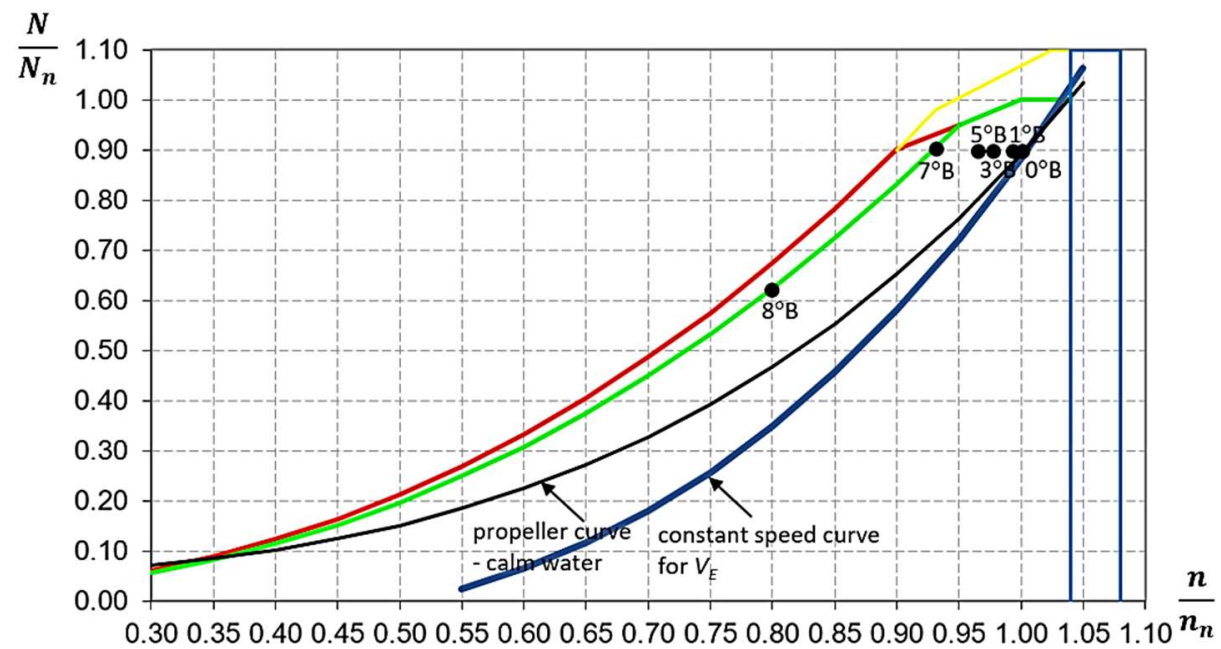

Criterion 4 - constant unit fuel consumption

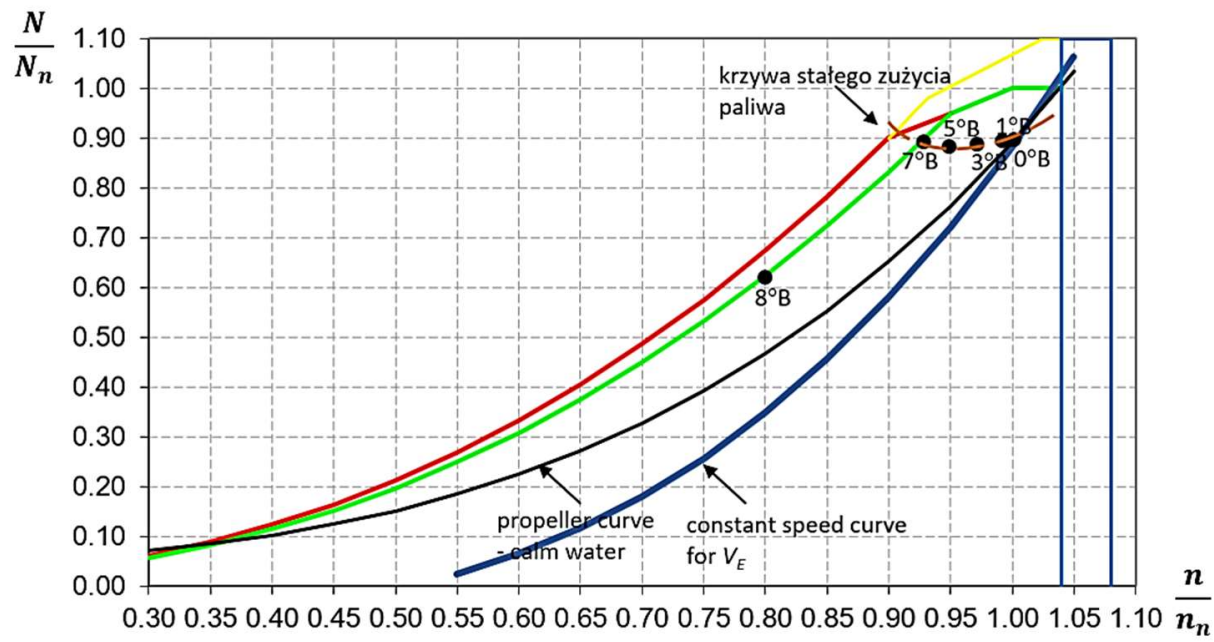

Fig. 3. Position of the operating point of the engine (power and speed) in variable weather conditions (BN number) and for different engine control criteria 

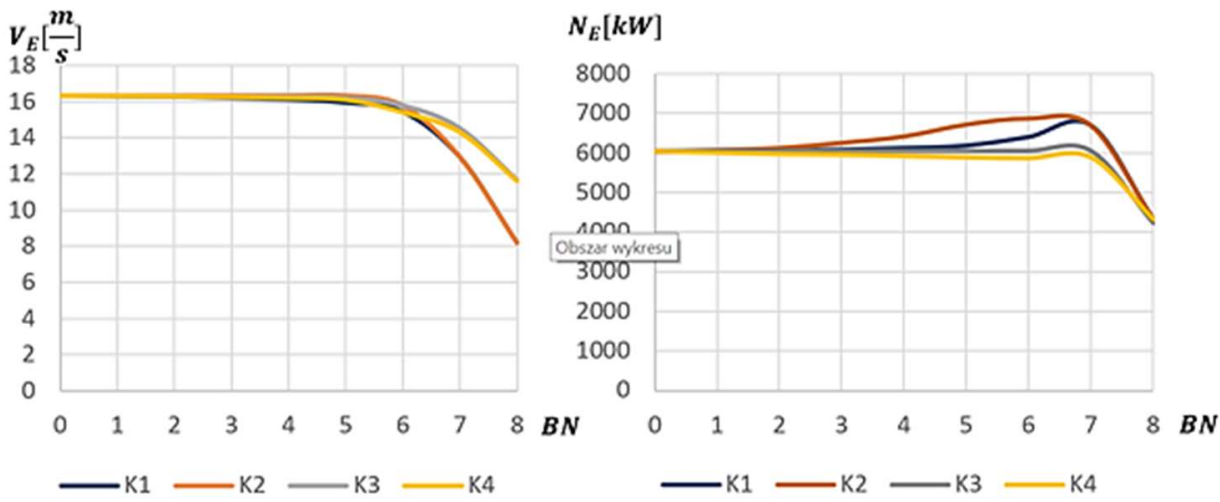

Fig. 4. The speed of the ship and the power of the propulsion engine in changing weather conditions and for various engine control criteria.
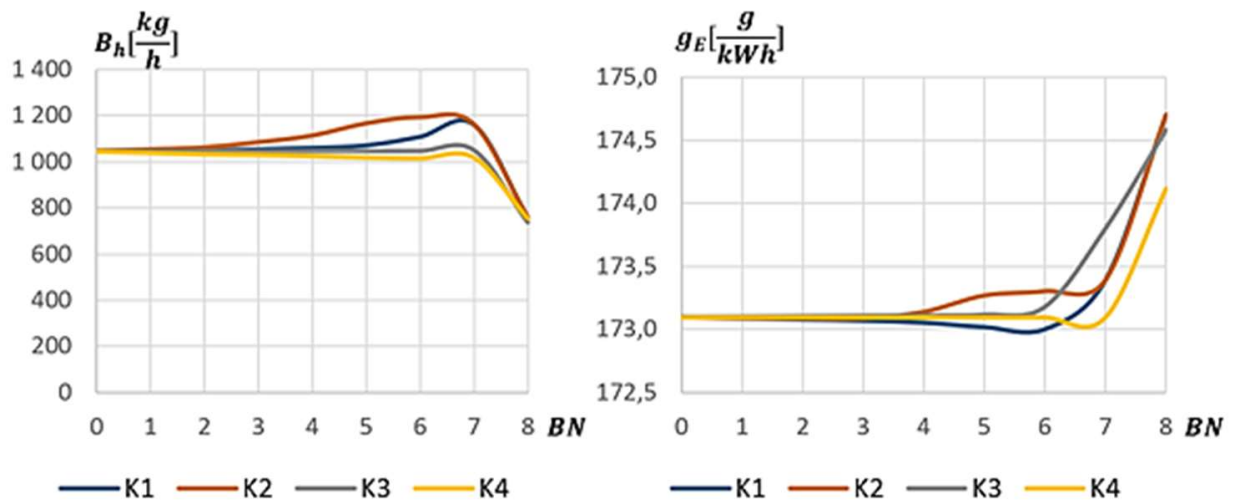

Fig. 5. Hourly and specific fuel consumption in variable weather conditions and for various engine control criteria.

The calculations show that with the increase in the Beaufort number (BN) the unit fuel consumption, for various engine control criteria, does not change in a large extent, while the speed of the ship as well as the engine power changes considerably (Fig. 4). This ultimately has a major impact on the total fuel consumption of the selected shipping route.

\section{AVERAGE SHIP FUEL CONSUMPTION ON A NAVIGATION LINE IN STATISTICAL WEATHER CONDITIONS}

The presented calculations of specific (or hourly) fuel consumption in changing weather conditions (Figure 5) show that it changes in a small range and depends mainly on engine power. The engine power depends on the selection of the control criterion and on the criterion of choosing the optimal route for sailing, for example maintaining a constant speed of the ship. Therefore, the average statistical fuel consumption can be predicted based on the average statistical power of the propulsion and the average operating speed of the vessel on the selected navigation route, on which average statistical weather conditions occur.

The article (Szelangiewicz and Żelazny, 2006) presents the algorithm and results of calculations of statistical average operating speed of a ship in statistical weather conditions for various types of ships and various shipping lines. The calculations were made for statistical averages (seasonal) of weather parameters (included in atlases (Hogben and Lumb, 1967, Hogben et. all, 1986)) occurring on these shipping lines.

The average statistical hourly fuel consumption was calculated for a container ship with parameters:

- $\quad L=140.14 \mathrm{~m}, B=22.3 \mathrm{~m}, d=8.25 \mathrm{~m}, \nabla=17290 \mathrm{~m}^{3}$,

- $\quad N_{n}=6930 \mathrm{~kW}, n_{n}=2.331 / \mathrm{s}, D_{P}=5.20 \mathrm{~m}$,

and for shipping routes:

- $\quad$ Route No. 2b (Eastern USA-Western Europe, northern route, "difficult" due to weather conditions), 
- $\quad$ Route No. 5b (Indonesia-Japan; easy due to weather conditions).

The results of calculations are shown in Figure 6.

Container ship - the operational speed $V_{Z E}=8.44 \mathrm{~m} / \mathrm{s}$

Route No. 2b

Route No. $5 b$

Histogram of speed

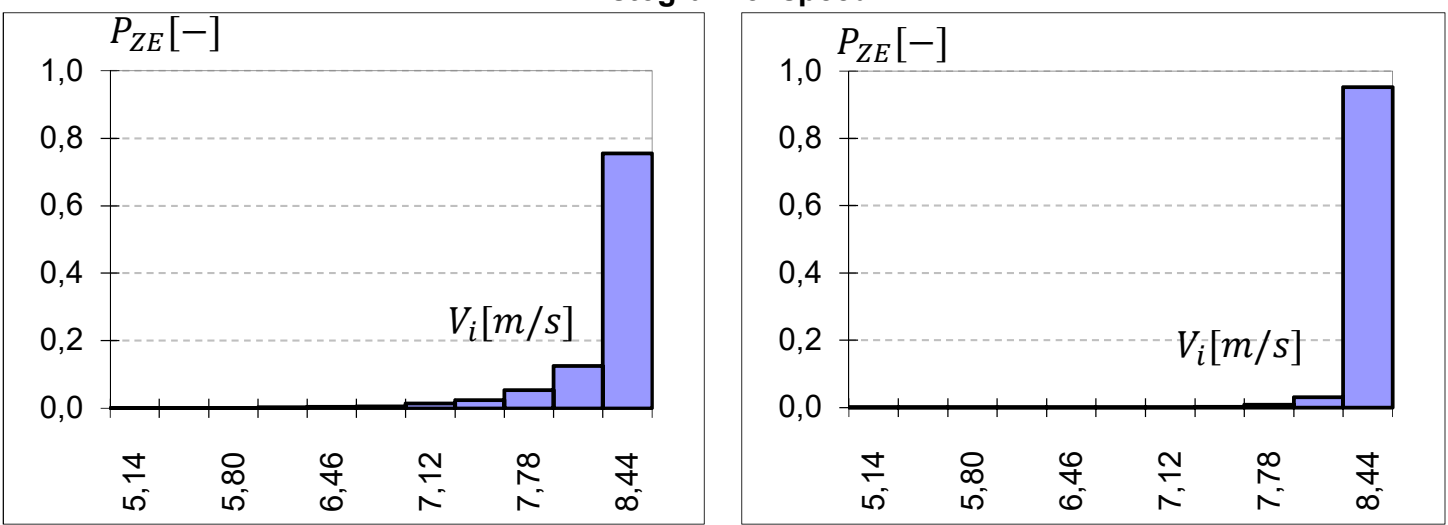

$\bar{V}_{E}$ - average statistical operating speed along the shipping route

$$
\bar{V}_{E}=8.19[\mathrm{~m} / \mathrm{s}]
$$

$\bar{V}_{E}=8.40[\mathrm{~m} / \mathrm{s}]$

$P_{Z E}$ - the probability of maintaining the operational speed

$$
P_{Z E}=0.75
$$

$P_{Z E}=0.95$

Power engine drive histogram
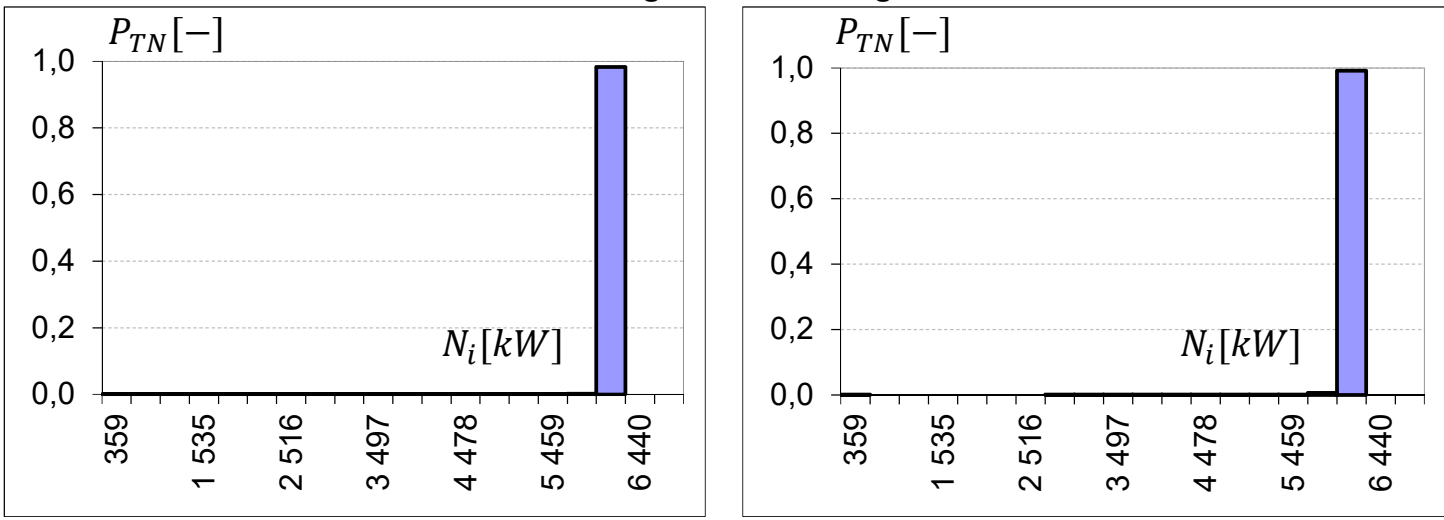

$\bar{N}$ - statistical average power of the propulsion engine along the shipping route

$$
\bar{N}=6164[\mathrm{~kW}]
$$

Histogram of unit fuel consumption
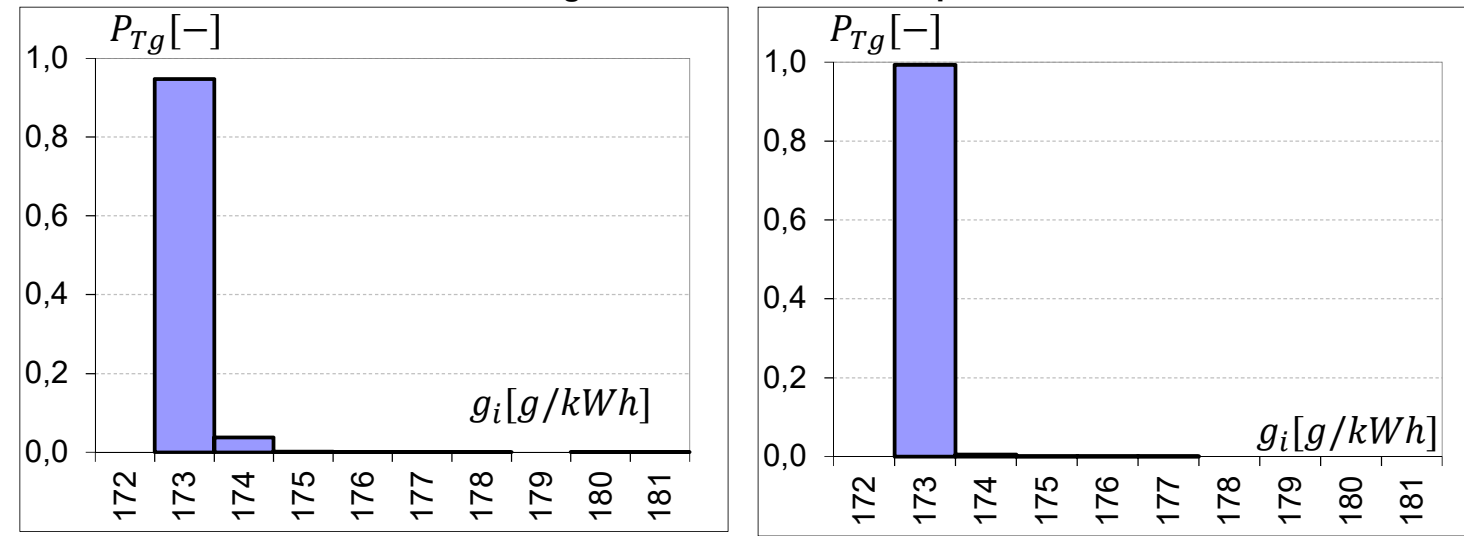

unit fuel consumption on calm water $g=173.00 \mathrm{~g} / \mathrm{kWh}$

$\bar{g}$ - average, statistical specific fuel consumption along the shipping route $\bar{g}=173.049 \mathrm{~g} / \mathrm{kWh}$

$\bar{B}_{h}$ - average, statistical hourly fuel consumption along the shipping route

$$
\bar{B}_{h}=1199.2 \mathrm{~kg} / \mathrm{h}
$$

$\bar{g}=173.006 \mathrm{~g} / \mathrm{kWh}$

$\bar{B}_{h}=1198.9 \mathrm{~kg} / \mathrm{h}$

Fig. 6. Histograms and average statistical parameters (ship speed, engine power and fuel consumption) in variable statistical weather conditions on selected shipping lines 


\section{CONCLUSIONS}

1. The results of the calculations show that specific or hourly fuel consumption and average statistical fuel consumption do not change to a large extent depending on the route of navigation (route $2 b$ and $5 b$ ). However, the total fuel consumption for the entire shipping route will be very different, because the speed of the ship will change significantly and the cruise time will be longer on selected shipping routes.

2. The calculation results presented were made for one selected shipping route - maintaining a constant speed of the ship.

3. The article presents the results of calculation of statistical averages of operational parameters of the ship (speed, engine power, fuel consumption) only for two selected shipping routes. Such calculations may be made for any ship and any shipping route in weather conditions on this route.

4. The calculations are made for statistical weather data (seasonal). Using the developed computer program, simulation calculations of the ship's operational parameters can be made, including the length of the sailing route and the cruise time in actual, instantaneous weather conditions.

\section{REFERENCES}

Wiśniewski, B. (1991). Problemy wyboru drogi morskiej. Gdańsk: Wydawnictwo Morskie. Program SPOS Fleet Management (2009). Meteo Consult BV, The Netherlands, V. 7.0.0.1.

Bon Voyage System (BVS) voyage optimization software (2016). Applied Weather Technologies (AWT), Kifer Court. Sunnyvale CA 94086. V. 7.1.

Szymański, M. and Wiśniewski, B. (2016). Application of Bon Voyage 7.0 (AWT) to programming of an ocean route of post-Panamax container vessel in transpacific voyage Seattle - Pusan 26.08.2015, 1600UTC-05.09.2015, 2100UTC. SCIENTIFIC JOURNALS OF THE MARITIME UNIVERSITY OF SZCZECIN, Zeszyty Naukowe Akademii Morskiej w Szczecinie. 48(120), pp. 182-186.

Yuankang, Z. and Shipyard S. (1993). Estimation for power and specific fuel consumption for a vessel during voyage. In: $20^{\text {th }}$ International Congres on Combustion Engines. London: CIMAC.

Szelangiewicz, T. and Żelazny, K. (2008). Mean Long-Term Propulsion Engine Service Parameters of a Transport Ship Sailing on a given Shipping Route, Problemy Eksploatacji, Wydawnictwo Instytutu Technologii Eksploatacji - PIB, 3, pp. 103-111.

Geertsma, R.D., Negenborn, R.R., Visser, K. and Hopman, J.J. (2017). Pitch control for ships with diesel mechanical and hybrid propulsion: Modelling, validation and performance quantification. Applied Energy, 206(15), pp. 1609-1631.

Białostocki, N. and Konovessis, D. (2016). On the estimation of ship fuel consumption and speed curve: A statistical approach. Journal of Ocean Engineering and Science, 7(2), pp. 157-166.

Myung-II R. (2013). Determination of an economical shipping route considering the effects of sea state for lower fuel consumption. International Journal of Naval Architecture and Ocean Engineering, 5(2), pp. 246-262.

Szelangiewicz, T. and Żelazny, K. (2006). A Relations Between an Ocean Route and Ship Size and the Mean Long-Term Ship Speed, SCIENTIFIC JOURNALS OF THE MARITIME UNIVERSITY OF SZCZECIN, Zeszyty Naukowe Akademii Morskiej w Szczecinie. 11(83), pp. 307-317.

Hogben, N. and Lumb F.E. (1967). Ocean Wave Statistics, National Physical Laboratory, London.

Hogben, N., Dacunha N.M.C. and Olliver G.F. (1986). Global Wave Statistics, BMT. 